\title{
Robótica Pedagógica e Currículo do Ensino Funda- mental: Atuação em uma Escola Municipal do Projeto UCA
}

\author{
Educational Robotics and the Elementary School Curriculum: The Practice in a Mu-
} nicipal School UCA Project

João Vilhete Viegas d'Abreu

Núcleo de Informática Aplicada à Educação

NIED/UNICAMP

Rua seis de Agosto, 50, CEP: 13083-970, Campinas -SP

jvilhete@unicamp.br

\author{
Bruno Leal Bastos \\ Instituto de Artes - IA/Unicamp, Departamento de Multi- \\ meios, Rua Elis Regina, 50, CEP 13083-854 \\ Campinas - SP \\ bruno.leal.bastos@gmail.com
}

Resumo Este artigo tem por objetivo descrever o processo de utilização da Robótica Pedagógica - RP, no contexto da formação de professores do projeto Um Computador por Aluno, UCA/Unicamp, desenvolvido entre 2011 e 2014 na Escola Municipal Elza Maria Pellegrini de Aguiar, localizada em Campinas, SP. O estudo objetivou tanto registrar e analisar o processo de formação de professores para o trabalho com a Robótica Pedagógica, numa vertente mediadora entre os conhecimentos cientificos e os conhecimentos escolarizados, quanto, especificamente, compreender como os professores que ensinam, em estreita relação com os alunos que aprendem, concretizam a noção de transposição didática utilizando-se da Robótica Pedagógica e do conceito de convergência interdisciplinar. O estudo contextualiza-se em duas fases distintas. A primeira desenvolvida entre agosto de 2011 e dezembro de 2012 e a segunda, entre junho de 2013 e julho de 2014. Participaram do estudo duas professoras de duas turmas de $5^{\circ}$ ano ( $A$ e B) do Ensino Fundamental. Como pressupostos teóricos, o trabalho dialoga, basicamente, com autores que discutem os conceitos de Robótica Pedagógica, Transposição Didática e Currículo. A noção de Convergência Interdisciplinar é apresentada e permeia os fazeres dos sujeitos. A metodologia de pesquisa tem como base a abordagem qualitativa, obtendo como resultado a evidência da importância da formação de professores para a utilização das noções de transposição didática e convergência interdisciplinar nos processos de ensino e de aprendizagem.

Palavras-Chave: Robótica Pedagógica, Formação de Professores, Currículo, Transposição Didática

\begin{abstract}
This article aims to describe the process of using the Educational Robotics - RP in the context of the project teacher training One Laptop per Student - named UCA/Unicamp -, developed between 2011 and 2014 at the Municipal School Elza Maria Pellegrini de Aguiar, located in Campinas, SP. The study aimed to both record and analyze the teacher training process to work with the Pedagogical Robotics, a mediator slope between scientific knowledge and the scholar knowledge, as well as, specifically, to understand how teachers, in close relationship with learning students, embody the notion of didactic transposition using the Pedagogical Robotics and the concept of interdisciplinary convergence. The study is contextualized in two distinct phases. The first, developed between August 2011 and December 2012 and the second between June 2013 and July 2014. Two teachers from two classes of 5 th year (A and B) of elementary school took part in the
\end{abstract}


studies. As theoretical assumptions, the work dialogues basically with authors discussing the concepts of Educational Robotics, Didactic Transposition and Curriculum. The notion of Interdisciplinary Convergence is presented and permeates the doings of the subjects. The research methodology is based on the qualitative approach resulting in an evidence of the importance of teacher training for the use of didactic transposition of ideas and interdisciplinary convergence in the teaching and learning processes.

Keywords: Educational Robotics, Teacher Training, Curriculum, Didactic Transposition 


\section{Introdução}

Este artigo descreve o processo de utilização da Robótica Pedagógica (RP) na educação, especificamente, no contexto do projeto Um Computador por Aluno (UCA/Unicamp), desenvolvido entre 2011 e 2014 na Escola Municipal Elza Maria Pellegrini de Aguiar, localizada em Campinas, SP.

O estudo teve como objetivo geral registrar e analisar o processo formativo de professores para o trabalho com a Robótica Pedagógica, numa vertente mediadora entre os conhecimentos científicos e os conhecimentos escolarizados; e, por objetivo específico, compreender como os professores que ensinam, em relação com os alunos que aprendem, concretizam a noção de transposição didática utilizando-se da Robótica Pedagógica e do conceito de convergência interdisciplinar.

O processo de formação de professores requer que se problematize o próprio objeto para o qual se está propiciando tal formação. Assim, as questões direcionadoras da pesquisa pautaram-se em compreender: "Como a Robótica Pedagógica pode se constituir em ferramenta mediadora da transposição didática dos conceitos científicos para os saberes escolarizados?" e, "A Robótica Pedagógica possibilita convergências interdisciplinares ao longo da transposição dos conhecimentos científicos aos saberes escolarizados?" Para tanto, estiveram juntos em tal empreitada acadêmica: pesquisadores da Universidade, professores e alunos de uma escola municipal, tendo a própria sala de aula como palco da produção deste conhecimento que ora passa a ser narrado.

$\mathrm{O}$ estudo apresenta-se descrito em duas fases distintas: a primeira desenvolvida entre agosto de 2011 e dezembro de 2012 e a segunda, entre junho de 2013 e julho de 2014. Com base no conceito de Transposição Didática (Chevallard apud Lopes e Macedo [1]), o artigo descreve uma experiência de formação de professores na Escola Municipal Elza Maria Pellegrini de Aguiar, localizada em Campinas, SP, da qual participaram duas professoras do ensino fundamental com suas duas turmas, respectivamente, o $5^{\circ}$ ano A e o $5^{\circ}$ ano $\mathrm{B}$, desenvolvida por meio de oficinas de trabalho, na própria sala de aula.

Ao longo do texto serão abordados conceitos estruturantes do estudo, tais como: Robótica Pedagógica (RP), Transposição Didática (TD) e Convergência Interdisciplinar (CI), como vemos a seguir.

Robótica Pedagógica pode ser definida como a área do conhecimento que utiliza os conceitos das engenharias e demais Ciências no processo de concepção, construção, automação e controle de dispositivos robóticos com propósitos educacionais.

Com relação à noção de Transposição Didática, aderimos à contribuição de Chevallard apud Lopes [1] ao afirmar que transposição didática é precisamente a transição de um conhecimento, considerado como uma ferramenta a ser colocada em uso, para algo a ser ensinado e aprendido. Assim, ao mesmo tempo em que é uma transição entre saberes, a transposição didática consiste no trabalho de realizar essa transição, o trabalho de transformar um objeto de saber a ensinar em um objeto de ensino. Na escola, tendo como base o currículo escolarizado, o saber das Ciências, ou conhecimento científico há que sofrer um processo de transposição no processo de ensino para que seja assimilado, modificado, adaptado aos padrões sociais e culturais e, finalmente, haja a efetiva aprendizagem.

O conceito de Convergência Interdisciplinar se constituiu ao longo do estudo como sendo a utilização de vários conceitos das áreas das Ciências de Referência (Física, Matemática, Engenharias, Geografia dentre outras), que se identificam, se conectam e se concretizam em uma ação ou objeto. Objeto este construído durante o estudo como um dispositivo da Robótica Pedagógica (RP).

Expressos os conceitos que subsidiaram a experiência investigativa, faz-se necessário uma breve contextualização histórica do campo de conhecimento em discussão, isto é, da Robótica Pedagógica.

O estudo da RP teve início nos EUA, no início dos anos 80, com a pesquisa de Seymour Papert e a Linguagem de Programação Logo. No Brasil, a RP teve os seus primeiros estudos desenvolvidos dentro de universidades como a Universidade Estadual de Campinas (Unicamp), Universidade Federal do Rio Grande do Sul (UFRGS) e Universidade Federal do Rio de Janeiro (UFRJ). No Brasil, projetos de pesquisa mais recentes nesta área são desenvolvidos em instituições educacionais como o Grupo Warthog Robotics, vinculado ao Instituto de Ciências Matemáticas e de Computação (ICMC) da USP, em São Carlos, Núcleo de Informática Aplicada à Educação (NIED/UNICAMP), em Campinas, Universidade Federal do Rio Grande do Norte (UFRN), em Natal, dentre outros. Nos Estados Unidos podemos citar Carnegie Mellon University (CMU), projeto da K-12 STEM Education Materials voltado para o desenvolvimento ou melhoria de cursos que utilizam robótica como uma ferramenta para o ensino. Do ponto de vista histórico, a partir da década de 1980, usando como marco o Projeto Educação com Computador- Educom [2], do ano de1983, a prática de inserção da Robótica Pedagógica ao uso de tecnologias na educação vem sendo desenvolvida. Mais precisamente, em 1987, junto com o aprendizado da Linguagem de Programação LOGO, inicia-se no Núcleo de Informática Aplicada à Educação NIED/UNICAMP, os primeiros projetos voltados para o uso do computador para controlar dispositivos robóticos. Nesse percurso, em 1989, o 
NIED realizou a primeira Oficina de RP, ministrada por um pesquisador do Massachusetts Institute of Technology (MIT, no EUA) com o objetivo de formar os pesquisadores daquele Núcleo para utilização de robótica no contexto educacional. Na década de 1990, com a implantação de computadores MSX, de 08 bits, a Robótica Pedagógica passou a ser desenvolvida no denominado ambiente LEGO-Logo no qual Kits LEGO eram utilizados para realizar atividades de robótica educacional. A partir de 1993, coube ao NIED desenvolver atividades de formação dos professores dos Centros de Informática na Educação (CIEds, hoje, Núcleo de Tecnologia Educacional NTE) ao longo do país.

Na década de 2000, o grande destaque da RP foi a criação da Olimpíada Brasileira de Robótica (OBR) [3], que teve suporte do Ministério da Ciência e Tecnologia (MCT), Conselho Nacional de Desenvolvimento Científico e Tecnológico (CNPq) e Ministério da Educação em parceria com a Fundação Nacional de Desenvolvimento da Educação (FNDE/MEC) [4]. Nesta década, a partir de 2008, foi criado o Workshop de Robótica Educacional WRE [5], um fórum científico com os propósitos de: capacitar professores do ensino médio e fundamental para inserir a Robótica Educacional nos conteúdos das disciplinas de matemática e física; expor resultados de pesquisas e possibilitar a troca de experiências acerca da utilização da Robótica Educacional como uma ferramenta interdisciplinar e, discutir aspectos técnicos e educacionais do uso da robótica envolvendo temas como: robótica na escola, formação de professores de robótica, competições de robótica, dentre outros.

Denota-se, portanto, que, desde a sua origem, a RP vem evoluindo tanto em pesquisas desenvolvidas em universidades quanto em fóruns e congressos que discutem como o seu uso pode contribuir para o desenvolvimento científico e tecnológico do Brasil e do mundo. Do ponto de vista do continente europeu e dos Estados Unidos, vale citar projetos voltados para o uso da RP no ensino, como:

TERECoP -(Teacher Education on Robotics) trata-se de um projeto implementado com a participação de 08 instituições educacionais europeias, de 06 países, com o objetivo de desenvolver atividades de caráter construtivista e construcionista para o ensino médio, com base na construção de robôs programáveis [6]; Hummingbird Duo Projects [7], trata-se de um "open source robot-designing kit" que permite níveis de aprendizagem de robótica para estudantes a partir de quarta série; Projeto Arts \& Bots da Carnegie Mellon University [8], trabalha a questão da inclusão de conteúdos tecnológicos no ensino fundamental e médio, num contexto que denominam de "A Robótica Comunitária, Educação e Tecnologia para Empodera- mento". O projeto explora a inovação e a implantação de tecnologias robóticas socialmente significativas.

Este artigo está assim organizado: na seção 1 fez-se um panorama geral envolvendo o histórico da RP. A seção 2 apresenta uma contextualização do projeto UCA/Unicamp no processo de formação dos professores. $\mathrm{Na}$ seção 3, discute-se a robótica pedagógica e a (re) construção do conceito de Transposição Didática. A seção 4 aborda a metodologia da pesquisa. A seção 5 evidencia os resultados e discussão. Na seção 6, trazemos as conclusões e, por fim, na seção 7, os agradecimentos. A seguir, apresenta-se a contextualização do projeto UCA/Unicamp e sua relação com a formação de professores.

\section{Contextualização do projeto UCA/Unicamp no processo de forma- ção dos professores}

Desde o princípio, a robótica foi trabalhada mais no contexto técnico do que pedagógico. Dessa forma, a abordagem da robótica em cursos como engenharia elétrica ou mecânica acabou tendo uma grande aceitação tendo se mostrado útil para o aprendizado das teorias estudadas nesses cursos. Entretanto, quando a robótica ultrapassou as fronteiras das universidades e começou a ser ensinada em escolas (de níveis fundamental e médio), os professores sentiram dificuldade para adaptá-la aos conteúdos do currículo escolar. Isso aconteceu, porque, em muitas escolas, sobretudo nas particulares, a robótica foi e ainda hoje é introduzida, apenas, como atividade extracurricular para poucos alunos no contra turno, ensinada, muitas vezes, por técnicos de informática e não por professores dos devidos componentes curriculares. Silva [9], em sua pesquisa de doutorado realizada em uma escola de ensino fundamental I, em Natal, RN, desenvolveu atividades que visavam à construção de protótipos robóticos pelas crianças - tendo como base a teoria sóciohistórica de Vygotsky - como forma de desenvolver as chamadas Zona de Desenvolvimento Proximal, (ZPDs), que proporcionassem o aprendizado de conceitos científicos. As atividades na escola foram desenvolvidas no formato de oficinas. Entretanto, os resultados da pesquisa demonstram que um dos fatores limitantes desse trabalho foi o pouco contato dos professores da escola com os alunos que participaram das oficinas. Zilli [10], na sua dissertação de mestrado analisa o uso da Robótica Educacional em escolas de ensino fundamental de $5^{\mathrm{a}}$ a $8^{\mathrm{a}}$ séries (atual $6^{\circ}$ a $9^{\circ}$ - Anos Finais do Ensino Fundamental), de Curitiba (PR) como recurso pedagógico. O resultado da pesquisa aponta que a tecnologia em questão ainda é um desafio para a realidade escolar, em relação a sua implantação no currículo da escola. Campos [11], cujo trabalho 
buscou identificar as características da integração da robótica como recurso tecnológico no currículo, mostra que essa integração possui aspectos complexos como a relação tempo/espaço, o (des) preparo da equipe pedagógica e a relação entre a robótica e outros saberes. Isto é, um projeto de integração de robótica como tecnologia ao currículo precisa contemplar de forma ampla também os conhecimentos referentes à robótica e à tecnologia, no intuito de permitir ao educando estabelecer relações mais complexas sobre a tecnologia e seu próprio processo de aprendizagem.

Portanto, os relatos desses pesquisadores apontam que: houve pouco contato dos professores da escola com os alunos que participaram das oficinas; persiste o desafio de integração da robótica com o currículo; há a necessidade de um processo formativo de professores para as complexidades que se apresentam na utilização da Robótica Pedagógica na escola.

Esses estudos (dentre tantos outros não apontados neste texto) denotam situações que podem ser superadas com a introdução do ensino da RP no currículo escolar das crianças e jovens, para que professores atuem em suas práticas, a partir das noções didáticas possibilitadoras da transposição dos conceitos das Ciências de Referência (por exemplo, Física, Matemática, Engenharias, Geografia, dentre outras) para o conhecimento escolarizado. Ou seja, de forma a que os alunos compreendam e enxerguem o sentido de tais aprendizagens para seu contexto de vida diminuindo suas dificuldades de compreensão dessas matérias escolares.

No contexto do projeto Um Computador por Aluno (UCA) [4], a formação de professores e alunos têm buscado, a partir da realidade da escola, e com base no currículo, produzir conhecimentos científicos que auxiliem o aprendizado de conceitos que, na maioria das vezes, são somente anunciados e nunca trabalhados de forma contextualizada. Uma das atividades neste processo constitui-se pela formação dos professores para a apropriação concomitante à aplicação dos conhecimentos de robótica integrados ao currículo, prática que difere do processo tradicional de formação realizada descontextualizada da sala de aula, desvinculada do conteúdo curricular, em que o professor primeiro aprende e depois executa a atividade e a insere no currículo.

Em consonância com os propósitos do projeto UCA, as atividades de Robótica Pedagógica na escola municipal Elza Maria Pellegrini de Aguiar [12] buscou trabalhar a formação para que professores e alunos se apropriassem de conhecimentos do uso do laptop educacional classmate, associados à construção de dispositivos robóticos controlados por esse computador [13], numa vertente de ensino aprendizagem que associa o uso do laptop educacional como tecnologia móvel e construção/invenção de máquinas que estão no imaginário das crianças. O seu desenvolvimento possibilitou aos professores efetiva melhora nas práticas pedagógicas, na medida em que, paulatinamente, o desenvolvimento profissional orientou o desenvolvimento curricular [14] no que diz respeito à aplicação de conhecimentos, apresentados de maneira simples, passíveis de serem compreendidos por alunos do ensino fundamental, nas áreas de Física, Matemática, Geografia, Química, Português, História, dentre outras, como veremos a seguir ao abordarmos a Robótica Pedagógica e a (re)construção do conhecimento de transposição didática.

\section{Robótica Pedagógica e a (re)construção do conceito de transpo- sição didática}

A Robótica Pedagógica há muito vem se incorporando às práticas dos professores e o caso apresentado neste texto é apenas uma das muitas experiências que se desenvolvem Brasil afora. É bem verdade que não se atingiu, ainda, a universalização de tal prática, no entanto, não pode mais ser considerada uma novidade nas escolas de Educação Infantil, Fundamental e Médio. Assim, nas escolas onde se vivencia tal experiência, pode-se afirmar que a robótica faz parte do currículo.

Porém, como a Robótica Pedagógica se articula ao currículo? Primeiramente, há que se ter em mente que o currículo e a didática encontram-se articulados nas práticas de ensino dos professores e nas aprendizagens dos alunos. O currículo se constitui a partir da seleção e organização de experiências, práticas, saberes, conhecimentos. E, a tal seleção, corresponde sempre a uma visão e concepção de sociedade, uma visão de ser humano e de mundo. Para Lopes e Macedo [1], trata-se de uma produção cultural que faz parte da luta pela produção de significado, a própria legitimação. Para Silva [15], além da questão do conhecimento nas teorias do currículo, está a questão de identidade e de subjetividade. O currículo é feito de escolhas, mas também de práticas que o subjazem, sejam elas explícitas ou ocultas, prescritivas, formais ou problematizadoras. O campo do currículo também incorpora os conteúdos universais acumulados pela humanidade e os conhecimentos produzidos pelas disciplinas científicas dos diversos campos do conhecimento. Porém, como é amplamente sabido por todos, o currículo escolar se constitui pelas disciplinas escolares que, em sua gênese, guardam semelhança com as disciplinas de cunho científico, também denominadas Disciplinas de Referência. Para exemplificar, podemos citar a Matemática, a Biologia, a Química, a História e a Geografia enquanto disciplinas científicas responsáveis pelas pesquisas e produção de conhecimento científico, possibilitado- 
ras do avanço científico nessas áreas. O currículo escolarizado, por sua vez, tem nestas a sua principal referência em relação aos conteúdos e conceitos trabalhados com crianças e jovens da educação básica. No entanto, reside aqui uma diferença entre a Matemática, a História, a Geografia escolar, dentre outras matérias trabalhadas: daquelas (da Ciência) para estas (curricularizadas), há o que se denomina - pelos estudos dos campos da Didática e do Currículo - de Transposição Didática. A concepção de Transposição Didática foi desenvolvida por Chevallard, didata francês ${ }^{1}$, a partir de seus estudos acerca das diferenças epistemológicas entre o conhecimento matemático produzido pelos investigadores, cientistas desse campo, e a matemática ensinada na escola [1]. Chevallard mostra como o conhecimento da ciência matemática é modificado, geralmente, e simplificado ao ser ensinado na escola, na disciplina escolar Matemática. Isto é, nesse novo contexto - de ensino e de aprendizagem - o conceito é deslocado [1]. No ato de ensinar, preexiste uma intenção de um sujeito - o(a) professor(a) em relação a outro sujeito, o aluno (a quem é ensinado) - e não necessariamente é o professor quem procede a essa seleção, pois o conhecimento, ao chegar à escola, já passou por um filtro mais amplo, cuja base é a importância social que é conferida a esse conhecimento, pela sociedade em geral. Percebe-se, então, que a transposição didática envolve um processo de transição entre mundos distintos do conhecimento, porém, que se aproximam de alguma forma. Nesse processo de deslocamento e transição para o universo currículo-escolar, o processo de transposição didática passa pelo que Chevallard denomina de noosfera (ou intelligentsia do sistema de ensino, cujo controle cabe aos sistemas de ensino, à estrutura social mais ampla, ao círculo representado pelas pesquisas e pesquisadores sobre ensino, associações científicas e sindicais, professores, militantes). Ou seja, é a instância onde são pensadas e prescritas as práticas pedagógicas e os conteúdos de ensino. Cabe frisar que a instância social não é composta exclusivamente por pessoas, mas pelas instituições às quais essas pessoas estão ligadas [1].

No contexto da experiência com a Escola Municipal Elza Maria Pellegrini de Aguiar, desenvolveu-se uma ação formativa cujo objetivo pautava-se em oferecer subsídios práticos e conceituais relacionados à utilização da Robótica Pedagógica como mediadora da transposição didática de conceitos científicos com vistas à construção de saberes escolares em convergência interdisciplinar no contexto curricular. Os conceitos científicos trabalhados na RP foram transpostos das áreas das engenharias e da robótica industrial e contextualizados para

${ }^{1}$ Yves Chevallard é "Professor do Institut Universitaire de Formation de Maítres de l'Académie d'Aix-Marseille, da Universidade de Provence, na França. Tem pesquisas no campo da Didática, com particular interesse na Didática da Matemática. Sua principal obra é A transposição didática: do saber sábio ao saber ensinado. serem ensinados no ensino fundamental ao articular o concreto e o abstrato e aspectos cognitivos e lúdicos, para criar situações de aprendizagem e resolver problemas que envolveram: concepção, implementação, construção, automação e controle de um mecanismo [16]. Na concepção do dispositivo, foram discutidos o seu design, o porquê de se construir "aquela" máquina para realizar uma determinada tarefa e a sua função pedagógica. Na implementação, a discussão deu-se em torno de como o robô deve ser construído: com material de kits de montar, material alternativo do tipo sucata ou de uma mistura dos dois e, que componentes mecânicos eletroeletrônicos o robô deve possuir para funcionar [17]. Na construção, o trabalho consistiu na montagem do robô propriamente dito, utilizando e respeitando-se princípios mecânicos e elétricos que possibilitam o funcionamento das máquinas. $\mathrm{Na}$ automação e controle, o desafio consistiu em utilizar um software (Scratch) [18] com um ambiente de programação e comandos apropriados para controlar componentes eletroeletrônicos do robô, que propiciasse a realização, de forma automática, a tarefa para a qual foi projetado. Isso tudo é feito com vistas a explorar tanto a vertente de construção quanto a de programação [21].

Em todas as etapas desse processo pode ocorrer aprendizagem advinda das mais diferentes áreas científicas, fazendo emergir novas ideias tecnológicas capazes de serem apropriadas pelos professores e alunos, produzindo novos conhecimentos [13]. É nesse contexto de formação que se enquadra o processo de uso da RP na escola como atividade de pesquisa envolvendo alunos, professores.

No decorrer deste relato podemos acompanhar o processo pelo qual a concepção de Transposição Didática se operacionalizou na escola porquanto conceitos científicos, complexos, oriundos das engenharias e da robótica industrial foram trabalhados e, de alguma forma, simplificados e (re) contextualizados para que se procedesse ao ensino (e à aprendizagem) escolar no currículo da educação básica. Isso, por sua vez, sinaliza e afirma o cenário de uma educação coerente - com as transformações sociais, econômicas e políticas atuais-, na qual se deve ter um currículo voltado ao fortalecimento ao invés do fracasso daqueles que passam pela escola. Para Almeida [19], a Transposição Didática é necessária, ela está relacionada à forma de ensinar e de aprender e que ela precisa ser pensada dentro da realidade escolar brasileira. No item a seguir, por meio da experiência de construir um carro robô que transportava o computador classmate num sistema que possibilitava medir a distância percorrida pelo carro, apresenta-se a metodologia desenvolvida neste trabalho, na qual se pode perceber a Transposição Didática como "saber sábio" (aquele produzido pelos cientistas Dall'Asta e Brandão [20]) que foi passada para a construção dos robôs na forma de um "saber escolar". 


\section{Metodologia da pesquisa}

O desenvolvimento da pesquisa pautou-se em uma abordagem qualitativa, uma vez que esta permite ao pesquisador, por meio da observação e reflexão sobre a realidade, chegar mais perto da "perspectiva" dos sujeitos. Dessa forma, buscou-se compreender, numa dada realidade, ou seja, em uma escola pública de ensino fundamental, a complexidade do processo de formação docente para se apropriar dos conhecimentos da robótica como recurso pedagógico mediador para a transposição didática de conceitos das Ciências para o saber curricularizado da escola de educação básica, ambos em perfeita simbiose com a convergência interdisciplinar entre os conhecimentos. Para tanto, como instrumentos de coleta de dados foram utilizados filmagens, fotografias, observações in loco e registros escritos e problemas formulados pelos alunos, fundamentais para uma análise mais criteriosa do fenômeno em questão, em seu contexto natural. Neste sentido, o processo de formação dos professores se constituiu em duas fases distintas e suas respectivas etapas, conforme apresentadas a seguir.

\subsection{Primeira fase}

A primeira fase foi desenvolvida de agosto de 2011 a dezembro de 2012. Esta, por sua vez, foi subdividida em duas etapas, que serão sucintamente descritas na sequência.

\subsubsection{Etapa 1 - Oficinas Piloto}

Nesta etapa, os pesquisadores da universidade realizaram oficinas piloto, que foram oferecidas a todos os professores e à direção da escola municipal.

Esta fase ocorreu de agosto a dezembro de 2011. Durante esse período foram realizadas as interações iniciais com a escola. Tais interações tinham como objetivo a apresentação de vídeos, palestras e discussões com o intuito de sensibilizar a escola para o uso da Robótica Pedagógica junto com o laptop educacional classmate como forma diferenciada de se explorar o uso deste computador.

Com esta ação, o que se buscava na realidade era que surgissem, voluntariamente, professores interessados em trabalhar com a robótica.

Nesta etapa, a direção escolar convidou, além de 10 professores da escola, alunos de Ensino Fundamental I e II, de diferentes faixas etárias que, no contraturno, aprenderam a usar o laptop educacional classmate e passaram a auxiliar os professores nas tarefas de apropriação e uso desses computadores atuando como monitores dos pro- fessores. Foram oferecidas oficinas com duração de duas horas, realizadas no laboratório de informática da própria escola, as quais consistiam em montagem de dispositivos robóticos, elaboração de programas usando a linguagem de programação Scratch, ensino dos princípios básicos de controle de componentes eletroeletrônicos via computador e de princípios mecânicos das máquinas que estão no nosso dia a dia.

Ao longo deste processo, tanto os professores quanto os alunos monitores se mostravam extremante receptivos, envolvidos e interessados na implantação da Robótica Pedagógica na escola. Entretanto, ao final do processo, somente duas professoras do $5^{\circ}$ ano se interessaram, efetivamente, em trabalhar com a robótica. E foi com estas que as atividades foram desenvolvidas, resultando neste estudo.

\subsubsection{Etapa 2 - Descrição de atividade em oficina formativa}

Nesta etapa, foram realizadas as oficinas de robótica na sala de aula com as turmas do $5^{\circ}$ ano A e B.

O período desta etapa foi de março a dezembro de 2012. Entre março e junho, as atividades foram desenvolvidas com a professora e alunos do $5^{\circ}$ ano $\mathrm{A}$; e de agosto a dezembro, com os do $5^{\circ}$ ano B.

As oficinas desta etapa tinham duas horas de duração, realizadas semanalmente na escola pelos pesquisadores da universidade com a participação de todos os alunos e da professora daquela turma.

Os alunos eram divididos em grupos de forma a permitir que tivessem acesso a todas as atividades do ambiente de Robótica Pedagógica (design, construção, automação-programação e controle do dispositivo robótico). Durante a realização da etapa 2 , para cada oficina ministrada, as professoras e os alunos tinham como tarefa elaborar um relato do que foi trabalhado naquele dia.

A título de exemplo de atividade desenvolvida na escola, foi apresentado à classe de alunos de $5^{\circ}$ ano o desafio de construir um carro que pudesse transportar o laptop educacional classmate, conforme mostrado na Figura 1, sendo este o objeto mediador para se concretizar a compreensão das noções de transposição didática. 


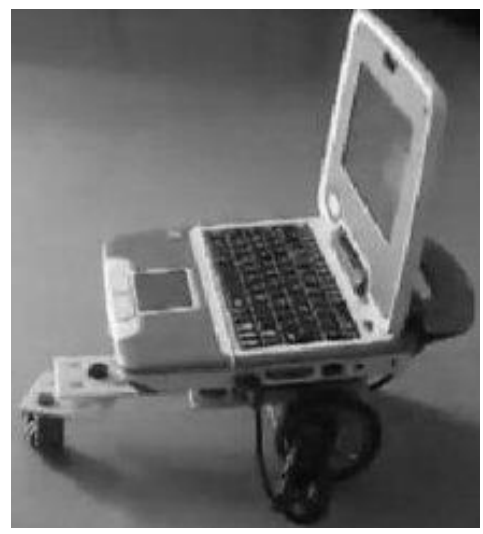

Figura 1: Carro robô transportando o laptop educacional classmate

O desafio apresentado tinha a ver com o fato de que no currículo dos alunos do $5^{\circ}$ ano, estes estudavam Unidades de Medida. Para tal, utilizando-se do objeto mediador "carro robô", direcionaram-se as atividades relacionadas ao estudo conceitual de Unidades de Medida correlacionados ao estudo dos conceitos científicos de espaço, tempo, velocidade, distância e potência, sendo estes inerentes ao deslocamento de um carro. Mas, para que o carro fosse utilizado pelos estudantes, havia que estruturá-lo, produzi-lo enquanto um artefato de engenharia e tecnologia (mas que também comporta valoração social, econômica, cultural). Foram os alunos que denominaram o carro de "carro robô".

O processo de construção do carro consistiu em montar uma estrutura composta de uma base (chassis), na qual se pudesse fixar dois motores para giro e tração traseira das rodas. Uma roda dianteira, sem tração, servia de apoio e de direção.

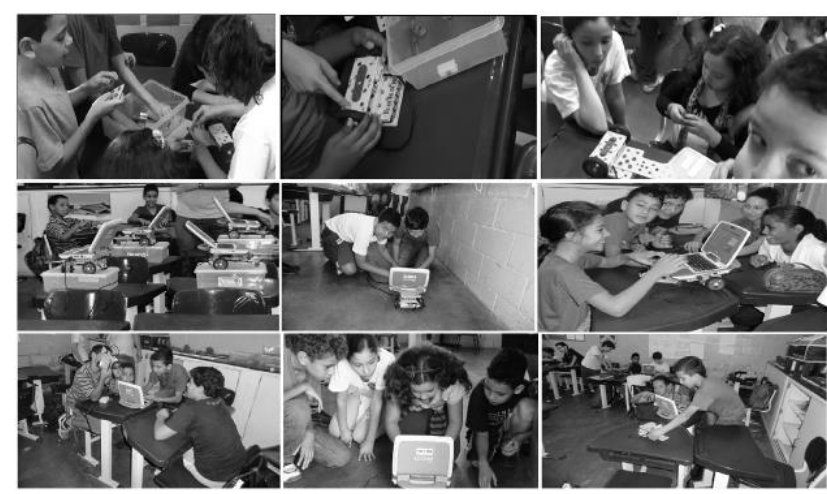

Figura 2: Sequência de fotos dos alunos construindo e programando o carro robô (artefato de engenharia, que envolve tecnologias e valorações sociais e subjetivas; econômicas e culturais).
Depois de construído o carro, foi perguntado aos alunos que tipo de problemas envolvendo o objeto de estudo deles (Unidades de Medida, "matemática") o "carro robô" transportando o laptop poderia ajudar a explicitar. $\mathrm{Na}$ aula seguinte, uma semana depois, os alunos trouxeram uma série de problemas, alguns descritos a seguir:

1. O robô leva o laptop em cima dele, se programarmos para girar por um minuto ele consumirá $30 \%$ da bateria. Sendo que ele tem 100\% de bateria, quanto sobrará de bateria?

2. O robô está programado para atingir a potência 255. Digamos que o robô do outro grupo está com o triplo da potência 255. Quantos ele tem a mais?

3. Na aula de robótica, participam 27 alunos em 5 grupos, 5 carros robôs e 5 laptops. Se em 3 segundos o carro robô roda 3 voltas, quantas voltas ele dará em 1 hora? E em 5 horas?

Em seguida "o carro robô" foi utilizado para solucionar os problemas elaborados. Esse processo se deu na forma de construção de tabelas, gráficos, desenhos, uso de trena para medir distância percorrida pelo carro, enfim, uma série de registros de experimento que auxiliaram os alunos na compreensão da matemática inerente ao deslocamento do "carro robô".

Do ponto de vista da transposição dos conceitos científicos para os saberes escolares evidenciados nos problemas formulados pelos alunos podemos citar: Tempo, Espaço, Distância, Velocidade, Potência, todos relacionados com a respectiva Unidade de Medida, conteúdo em estudo pelos alunos no desenvolvimento curricular, como descrito anteriormente. Ou seja:

-Tempo: Tempo gasto, pelo carro, em minutos ou segundos para deslocamento do ponto $\mathrm{A}$ ao ponto $\mathrm{B}$ na sala de aula, utilizando-se o relógio como recurso pedagógico medidor.

-Espaço: O espaço foi medido do ponto A ao ponto B da sala de aula. Utilizando como instrumento de medida a trena e espaço medido em metros.

-Distância: Distância, em metros, percorrida pelo carro, na sala de aula, do ponto A ao ponto B cuja medida fezse utilizando como recurso pedagógico, a trena;

-Velocidade: Velocidade do carro ao se deslocar do ponto A ao ponto B da sala, avaliada em função do tempo gasto para realizar o percurso. A medida foi feita experimentalmente: quanto mais lento o carro maior era o tempo gasto para realizar o mesmo percurso. 
-Potência: A potência foi medida, experimentalmente, em relação à velocidade de giro do motor cujo eixo estava conectado ao eixo da roda do carro. A transmissão do giro do motor para a roda do carro é feita por engrenagens. Engrenagem menor conectada no eixo do motor e engrenagem maior no eixo da roda do carro, possibilitando neste eixo menor giro e maior força, consequentemente maior potência do carro. Neste caso, a potência está relacionada a Unidades de Medida como: Tensão Elétrica em Volts, Corrente em Ampere expresso na forma de Torque no eixo do motor. Estes conceitos, provenientes da área das Engenharias (mecânica e elétrica) ainda não haviam sido aprendidos por aqueles alunos, entretanto, puderam, experimentalmente, ao interagir com o objeto "carro robô", avaliar seus efeitos.

Ao analisarmos os enunciados propostos pelos alunos, se expressa a transposição didática dos conceitos das Ciências de Referência, materializados na prática de aprendizagem quando da proposição de problemas formulados pelos próprios estudantes e evidencia-se que:

a) o enunciado 1 mostra que o aluno se utilizou de conceitos matemáticos de soma, subtração e porcentagem articuladas às noções relacionadas à unidade de tempo para formular o seu problema;

b) $\mathrm{O}$ enunciado 2 mostra que o aluno se utilizou de conceitos matemáticos de multiplicação e divisão aliados aos conceitos de física (potência) para formular o seu problema;

c) $\mathrm{O}$ enunciado 3 envolveu conceitos de multiplicação e unidades de tempo (horas, minutos e segundos) para formular o seu problema.

Os três enunciados denotam ser de problemas com soluções matemáticas factíveis. Entretanto, no caso do enunciado 2 , tecnicamente, em função do kit de robótica que os alunos estavam utilizando, o valor máximo para a potência do motor só podia ser de 255. Aparentemente o aluno cometeu um 'erro' ao formular o seu problema. Entretanto, como afirma [1] nem toda diferença entre o saber referência e o saber escolar é um erro. O importante neste caso é o papel de mediação da RP ao possibilitar com que o aluno explicitasse e testasse o seu saber escolar.

Nos três exemplos a Transposição Didática de conceitos matemáticos e físicos utilizados foi possibilitada pelo manuseio experimental que a RP propiciou, num contexto em que pudemos perceber Convergência Interdisciplinar. Ou seja, os conceitos científicos espaço, tempo, velocidade, distância e potência, convergiam de forma interdisciplinar com o estudo de Unidades de Medida. Para cada um desses conceitos físicos existe uma Unidade de Medida, e todos eles: hora em relação tempo; metro em rela- ção ao espaço; watts em relação à potência, etc. estão correlacionados e convergem em uma única ação que é o deslocamento do (objeto) carro. Os professores e os alunos compartilharam da mesma experiência, em um mesmo ambiente de aprendizagem, do manuseio e da materialização dos conceitos em seu processo de transposição, recontextualização e convergência interdisciplinar dos conceitos, reconfigurados agora em saberes escolarizados.

O fato de os alunos possuírem um objeto concreto (carro robô) que os ajudou a elaborar um problema real demonstrou ser uma forma de aprendizado de conceitos de matemática e física a partir de um contexto (social e cognitivo) no qual estavam envolvidos. Eles tiveram interesse em mensurar variáveis como tempo de duração da bateria do robô em função da tarefa por este realizada e número de voltas que o carro robô dá em uma hora.

Do ponto de vista curricular, alunos de $5^{\circ}$ ano ainda não detinham determinados conceitos, avançados para seu nível de formação, no entanto, os problemas por eles elaborados pressupunham formulações matemáticas complexas que, do ponto de vista experimental, puderam comprovar.

Com essa atividade, expressou-se uma forma de se fazer a transposição didática, mediada pela Robótica Pedagógica, que vai além do simples construir e controlar um dispositivo robótico via computador. Conforme já dito anteriormente, o software usado para programar os robôs é o Scratch, uma linguagem de programação de fácil manipulação na qual as crianças podem trabalhar com recursos de áudio e imagem, acrescido de comandos que permitem controlar a interface eletrônica similar a Arduino [22]. Na interface eletrônica são conectados motores, sensores, luzes, dentre outros componentes elétricos do robô. O Sistema Operacional instalado no laptop educacional para trabalhar com robótica é o Ubuntu versão 10.04 .

O material utilizado para montagem do "carro robô" foi da empresa Dual System Produtos e Serviços Ltda., numa versão denominada de Kit para Educação Tecnológica e Robótica, KTR - 12 .

Vale salientar que este tipo de material permite integrar peças do kit com outro material de padrão não comercial (sucata).

Em síntese, a primeira fase do processo de formação foi de atuação mais sistemática de pesquisadores da universidade junto às professoras e seus alunos, buscando criar condições que possibilitassem a realização, em sequência, da segunda fase.

Entretanto, em função dos acertos específicos inerentes ao projeto UCA, a segunda fase só pode ser iniciada em junho de 2013, conforme descrito a seguir. 


\subsection{Segunda fase}

Esta fase iniciou-se em junho de 2013 e se estendeu até julho de 2014, tendo como foco a preparação de professores para o desenvolvimento autônomo das atividades regulares de robótica pedagógica integradas ao currículo, sem a presença sistemática dos pesquisadores da universidade na escola.

Entretanto, embora os pesquisadores não tivessem presença constante na escola como ocorreu na fase anterior foi estabelecido um canal de comunicação permanente entre estes e as professoras. Ficou acordado que seriam realizadas visitas esporádicas dos pesquisadores à escola apenas em situações que envolvessem ações mais complexas como, por exemplo: a troca de versão de sistema operacional para controle da interface eletrônica dos kits de robótica, ensino de uso de novos componentes eletroeletrônicos e realização de reuniões.

As discussões e orientações sobre o desenvolvimento de atividades se deu, fundamentalmente, via e-mail. Para esta fase foi elaborado um material básico de apoio que descrevia, detalhadamente, as entradas e saídas da interface que controla os componentes eletroeletrônicos via laptop educacional classmate, continha também exemplos e desenhos de conexão de motores, sensores e lâmpadas na interface eletrônica; trazia exemplos de programas, em Scratch, para acionamento e controle de componentes eletroeletrônicos dentre outros tópicos que poderiam auxiliar a professora na resolução de eventuais problemas de ordem técnica durante a aula.

Além disso, ainda com vistas à preparação das professoras para esta fase, foram realizados encontros que se constituíram na atualização e recapitulação de conteúdos que haviam sido trabalhados até o final de dezembro de 2012. Na operacionalização desta prática, as professoras resolveram inserir outro desafio no processo: selecionaram alguns alunos para atuarem como monitores da própria turma, ajudando-as nas atividades de robótica.

Esse desafio das professoras evidenciou algo de muito positivo: o fato de se sentirem seguras para trabalharem a Robótica Pedagógica e passarem esta segurança para seus alunos numa relação em que estes poderão vir a atuar de igual para igual com as professoras, ensinando aos seus pares, os próprios colegas de classe.

Do ponto de vista metodológico, nas duas fases descritas foi realizada a preparação das professoras para assumirem sozinhas, de forma autônoma, o controle das atividades de robótica com suas classes.

Em resumo, a metodologia desenvolvida neste processo de formação consistiu na realização de Oficinas Piloto de Demonstração, devidamente registradas em Diários de Campo; apresentação de vídeos, palestras e discussões; sensibilização de professores, alunos e dire- ção escolar; atividades de formação de duas professoras e os seus respectivos alunos; acompanhamento presencial de pesquisadores da universidade às oficinas; $\mathrm{e}$, finalmente, o trabalho das professoras sob acompanhamento a distância feito pelos pesquisadores da universidade.

\section{Resultados e discussão}

Para análise e discussão dos resultados deste trabalho, retomamos as questões levantadas ao longo do artigo. Neste sentido, tem-se como ponto de partida o objeto de estudo desta pesquisa que buscava entender como a Robótica Pedagógica pode se constituir em ferramenta mediadora da transposição didática dos conceitos científicos para os saberes escolarizados num contexto em que este recurso foi utilizado no processo de formação de professores. Tanto a construção do "carro robô" quanto a sua utilização focada em um conteúdo curricular - Unidades de Medida -, que estava sendo estudado naquela ocasião, foi significativa para os alunos e para os professores. O objeto mediador "carro robô" possibilitou, por um lado, com que os alunos formulassem problemas correlacionados ao estudo dos conceitos de espaço, tempo, velocidade, distância e potência, inerentes a movimentos de um carro, e por outro lado, a transposição desses conceitos científicos para os saberes escolares. A evidência disso está na natureza dos problemas formulados pelos alunos, cujos enunciados evocavam a utilização das quatro operações matemáticas: adição, subtração, multiplicação e divisão, e, além disso, porcentagem e formulações matemáticas complexas que somente puderam ser comprovadas do ponto de vista experimental, ou seja, manuseando tais conceitos por meio do objeto por eles construído: "o carro robô". Vale destacar na formulação do enunciado do problema 2 o fato de que a potência do motor, tecnicamente, não atingiria o valor (3x255). Isso aparentemente indicava que o aluno cometeu um "erro" ao formular o seu problema, entretanto, tratava-se do processo de compreensão e assimilação pelos alunos ao promover a transposição do saber sábio/científico para o saber escolarizado, entre o saber de referência e o saber escolar, processo esse, fundamental na ação de aprendizagem. O importante, neste caso, é compreender o papel de mediação da RP ao possibilitar que o aluno explicitasse e testasse o seu saber escolar.

Em relação à convergência interdisciplinar abordada no estudo, percebeu-se que os conceitos científicos espaço, tempo, velocidade, distância e potência convergiam de forma interdisciplinar com o estudo curricular de Unidades de Medida. Para cada um desses conceitos científicos apontados existe uma Unidade de Medida (por exemplo, hora em relação tempo; metro em relação ao espaço; watts em relação à potência, etc.). Todos esses conceitos estão correlacionados e convergem em uma única ação 
que é o deslocamento do carro. Portanto, a Transposição Didática de conceitos matemáticos e físicos utilizados foi possibilitada pelo manuseio experimental que a RP possibilitou num contexto em que pudemos perceber a convergência interdisciplinar entre os conceitos das áreas da Física, da Matemática e Engenharias (Mecânica e Elétrica/Eletrônica).

\section{Conclusões}

No inicio deste estudo foi estabelecido como pergunta orientadora da pesquisa: "Como a Robótica Pedagógica pode se constituir em ferramenta mediadora da transposição didática dos conceitos científicos para os saberes escolarizados?" e, “A Robótica Pedagógica possibilita convergências interdisciplinares ao longo da transposição dos conhecimentos científicos aos saberes escolarizados?"

Ao longo deste artigo foram abordados conceitos estruturantes do estudo, tais como: Robótica Pedagógica (RP), Transposição Didática (TD) e Convergência Interdisciplinar (CI).

No exemplo de atividade discutida neste artigo pode ser demonstrado que esta propiciou convergências interdisciplinares ao longo da transposição dos conhecimentos científicos aos saberes escolarizados na medida em que a utilização do "carro robô" possibilitou aos alunos formularem questões cujas respostas envolviam o uso de conceitos científicos que, por sua vez, correlacionavam de forma interdisciplinar na ação de deslocamento do carro ao realizar um determinado percurso.

Do ponto de vista de Transposição Didática evidenciou-se com este trabalho a importância de sua utilização no desenvolvimento de atividades de Robótica Pedagógica, possibilitando a produção de saber escolar a partir do saber sábio dos cientistas. Isso potencializou a escola no seu papel de ambiente educativo. Neste sentido, a Robótica Pedagógica contribuiu com a escola ao propiciar condições para realização de atividades interdisciplinar integrada ao currículo do $5^{\circ}$ ano a partir da concepção, construção, automação e controle de dispositivos robóticos. Além disso, possibilitou um tratamento contextualizado do conhecimento, aprendizagens significativas a partir de ações que possibilitaram transformar o objeto de saber em objeto de ensino.

A Convergência Interdisciplinar definida como sendo a utilização de vários conceitos das áreas das Ciências de Referência que se identificam e se concretizam em uma ação, ou objeto, possibilitou a transposição do conhecimento científico ao conhecimento escolarizado. Isto é, a síntese de convergência dos conceitos de espaço, tempo, velocidade, distância e potência em ação concreta de deslocamento do objeto "carro robô".

Numa reflexão sobre o começo do processo formativo, no início da fase 1 , tanto os alunos quanto as professoras não tinham compreensão do ambiente de Robótica Pedagógica como um todo, que envolve construção, programação e controle automatizado do robô. No final desta fase, essa compreensão já foi constatada. $\mathrm{Na}$ fase $2 \mathrm{da}$ pesquisa, à medida em que os professores se apropriaram de conhecimentos nesta área, paulatinamente, adquiriram autonomia para trabalhar com os alunos, sem a presença frequente de pesquisadores da Universidade na escola. No final da fase 2, de certa forma, isso se evidenciou como uma garantia da continuidade da realização da atividade de robótica, mesmo depois de finalizado o projeto UCA/Unicamp.

\section{Agradecimentos}

Os autores agradecem à coordenação do projeto $\mathrm{UCA} /$ Unicamp e ao CNPq pelo apoio ao projeto "O Laptop Educacional e a Educação Baseada na Investigação: do estudo de fatos científicos para o fazer científico" (550382/2011-9). Agradecem também aos professores, alunos e à direção da escola Elza Maria Pellegrini de Aguiar, e aos mestrandos e bolsistas de Iniciação Científica. Foi com a colaboração de todos que este trabalho de formação pode ser realizado.

\section{Referências}

[1] A. C. Lopes, E. Macedo. Teorias de Currículo. São Paulo: Cortez. Apoio: FAPERJ, 95-96, 2011.

[2] J. A. Valente, Formação de Professores Diferentes abordagens Pedagógicas. In J. A. Valente, (Org.). O Computador na Sociedade do Conhecimento. NIED/UNICAMP, Campinas, 1999.

[3] Olimpíada Brasileira de Robótica OBR. Disponível em: <http://www.obr.org.br> Acesso em 08 de Setembro de 2015.

[4] Fundo Nacional de Desenvolvimento da Educação - FNDE Projeto um computador por aluno. Disponível em < http://www.fnde.gov.br/programas/programanacional-de-tecnologia-educacionalproinfo/proinfo-projeto-um-computador-poraluno-uca>. Acesso em 17 de agosto de 2015. 
[5] Workshop de Robótica Educacional - WRE. Disponível em: http://www.natalnet.br/wre2014/. Acesso em 08 de Setembro de 2015.

[6] TERECoP -Teacher Education. Disponível em: http://www.terecop.eu/. Acesso em 08 de Setembro de 2015.

[7] Hummingbird Duo Disponível em: https://www.kickstarter.com/projects/9382741938 2741938274194/hummingbird-duo-a-robotics-kitfor-ages-10-to-110. Acesso em 18 de Agosto de 2015.

[8] Projeto Arts \& Bots. Disponível em: < http://www.cmucreatelab.org/ > . Acesso em 08 de Setembro de 2015.

[9] A. F. Silva, RoboEduc: Uma Metodologia de Aprendizado com Robótica Educacional. Tese de Doutorado. Programa de Pós-Graduação em Engenharia Elétrica da Universidade Federal do Rio Grande do Norte -UFRN, Natal, RN, 2009.

[10] S. R. Zilli, A Robótica Educacional no Ensino Fundamental: Perspectivas e Prática. Dissertação de Mestrado Programa de Pós-Graduação em Engenharia de Produção da Universidade Federal de Santa Catarina, UFSC, Florianópolis, SC, 2004.

[11] F. R. Campos, Currículo, Tecnologias e Robótica na Educação. Tese de Doutorado, Pontifícia Universidade Católica de São Paulo - PUCSP, São Paulo, SP, 2011.

[12] EMEF.Elza - na Rede UCA (2012). Disponível em $<$ http://emefelza2010.blogspot.com>. Acesso em 18 de Agosto de 2015.

[13] J. V. V. D’Abreu, B. L. Bastos, G. F. A. O. Giachetto. Educational Robotics In One Laptop per Student-UCA Project In: Athenas Constructionism Proceedings. v.01. páginas 575 - 579, 2012.

[14] M. F. Garcia. O Ensino por Meio da Pesquisa: O projeto "Ciência na Escola". Tese de doutorado. Faculdade de Educação, FE-Unicamp, Campinas, SP, Brasil, Fevereiro, 2002.

[15] T. T. Silva, Documentos de Identidade: Uma Introdução às Teorias do Currículo. Belo Horizonte, Autêntica ISBN: 85-86583-44-8, BH, Brasil, 2000.

[16] J. V. V. D’Abreu, B. L. Bastos. Robótica Pedagó- gica: Uma Reflexão sobre a Apropriação de Professores da Escola Elza Maria Pellegrini de Aguiar. In Anais do II Congresso Brasileiro de Informática na Educação - CBIE-XIX Workshop de Informática na Escola, Unicamp, Campinas, SP, páginas 280-289, 2013.

[17] J. V. V. D’Abreu, J. G. Ramos, L. G. B. Mirisola. Ambiente de Robótica Pedagógica com Br-GoGo e Computadores de Baixo Custo: Uma Contribuição para o Ensino Médio In: Anais $22^{\circ}$ Simpósio Brasileiro de Informática na Educação e $17^{\circ}$ Workshop de Informática na Escola, Aracaju, SE, v.01. páginas $100-109,2011$.

[18] J. Maloney, M. Resnick, N. Rusk, B. Silverman, E. Eastmond, The Scratch Programming Language and Environment. In ACM Transactions on Computing Education (TOCE), vol. 10, no. 4, 2010.

[19] G. P. Almeida, Transposição Didática por onde começar, ISBN 978-85-249-0682-0, Ed. Cortez, São Paulo, SP, 2007.

[20] Dall'Asta, R. J. e Brandão, E. J. R. A Transposição didática em Softwares educacionais, Revista Linhas, V.5, nº2, ISSN 1984-7238, 2004.

[21] J. V. V. D’Abreu, M. F. Garcia. Robótica Pedagógica e Currículo In: Workshop de Robótica Educacional WRE, SBIA-SBRN-JRI, São Bernardo do Campo - SP, Brasil, páginas 01 - 06, 2010 .

[22] Arduino "Open-source physical computing platform". Disponível em <http://www.arduino.cc/>. Acesso em 17 de Agosto de 2015. 